REVISTA DE DERECHO UNED, NÚM. 8, 2011

\title{
EL OBJETO DEL ACUERDO EXPROMISORIO: REVISIÓN CRÍTICA DE SU ÁMBITO DE ACTUACIÓN SOBRE LAS OBLIGACIONES CONTRACTUALES, LEGALES Y EXTRACONTRACTUALES
}

\author{
M $M^{\mathrm{a}}$ Fernanda Moretón SAnZ. \\ Profesora Contratada Doctora \\ Departamento de $\mathrm{D}^{\circ}$ Civil de la UNED
}

Resumen: En este trabajo se analizarán cuáles son los requisitos de la novación y, en particular, cuáles, de entre dichos presupuestos, son aplicables al supuesto autónomo de la expromisión. Este acuerdo de sustitución pasiva, previsto en el artículo 1.205 del Código civil español, tiene la particularidad de que puede actuar sobre relaciones obligatorias contractuales, legales y extracontractuales. De modo que la expromissio podría operar sobre cualquier vínculo obligacional, independientemente del acto jurídico que haya dado lugar al nacimiento de la relación. A su vez, la fuente de la que dimana la relación en que se sustituye y libera el deudor, puede derivar de la ley, de un contrato y cuasicontrato, así como de ciertos actos y omisiones generadoras de responsabilidad civil. A estos y a otros extremos controvertidos, se dedicará este artículo.

Palabras clave: novación, expromisión, extinción de las obligaciones.

Abstract: In this investigation study the requirements of the novation and, in particular, which are applicable to the expromissio. This agreement of passive substitution, in the 1.205 of the Spanish civil Code, has the particularity that it can act on contractual, legal obligatory and torts. So the expromissio could operate on any obligatory. The origin of which emanates the relationship it is substituted and 
the debtor liberates, it can derive of the law, of a contract and cuasicontrato, and of responsibility. To these and other aspects, it's the object of this investigation.

Key words: novation, expromissio, extinction of the tort.

Sumario: I. CONSIDERACIONES PREVIAS SOBRE LOS REQUISITOS DE LA NOVATIO Y SU APLICABILIDAD AL ACUERDO EXPROMISORIO; II. EL OBJETO DE LA EXPROMISSIO: ÁMBITO DE ACTUACIÓN DEL ACUERDO DE SUSTITUCIÓN PASIVA: 1. Las obligaciones susceptibles de ser modificadas o extinguidas: examen de su evolución histórica; 2. La sustitución del sujeto pasivo en las relaciones obligatorias: la capacidad de las obligaciones para ser modificadas independientemente de la fuente de la que procedan: A) Las obligaciones jurídico-privadas como relaciones modificables; B) El pacto de intransmisibilidad pasiva; C) El caso de la obligación natural como relación obligatoria en que puede ser sustituido el deudor originario; D) La responsabilidad extracontractual como obligación asumible por un tercero ajeno; 3 . La transmisión de la conducta comprometida: la expromisión en las obligaciones de dar, hacer y no hacer: A) Límites a la transmisibilidad de la conducta prometida por el deudor; B) El caso de las obligaciones negativas: la conducta omisiva del deudor como obligación transmisible; C) Cambio de deudor en las obligaciones bilaterales y unilaterales; 4. Referencia al cambio de deudor en la denominada novación o modificación de la hipoteca; III. REFLEXIONES CONCLUSIVAS.

\section{CONSIDERACIONES PREVIAS SOBRE LOS REQUISITOS DE LA NOVATIO Y SU APLICABILIDAD AL ACUERDO EXPROMISORIO}

Los requisitos contemplados por las fuentes romanas fueron evolucionando y como el concepto de obligatio, se adaptaron a las cambiantes necesidades jurídicas ${ }^{1}$. En este sentido, en la época clásica, presupuesta una obligación precedente ${ }^{2}$ se exigía para que operase la novatio, adicionalmente:

${ }^{1}$ Vid., Moretón SANZ, La asunción espontánea de deuda, Valladolid, Lex Nova, 2008 y la bibliografía allí citada; en particular, la referida en el capítulo segundo sobre «El proceso codificador: Proyectos y antecedentes», págs. 83 y sigs.

${ }^{2}$ Cualquier obligación civil será novable: la nacida de un legatum per damnationem; la futura; la condicional, así como la sometida a término inicial (vid., BonIfacio, La novazione nel Diritto romano, Napoli, 1959, $2^{\text {a }}$ ed., págs. 85 a 93). 
a) Una modificación estructural o aliquid novi ${ }^{3} \mathrm{y}$

b) algo idéntico a la relación precedente o idem debitum ${ }^{4}$.

De modo que, mediante la conclusión de una stipulatio, el efecto novatorio era totalmente independiente del animus novandi, ya que el protagonismo residía en las formalidades que revestían a la estipulación. Solemnidades éstas de la época clásica que cedieron en favor del ánimo novatorio; en definitiva, en la justinianea, el requisito soberano radica en la voluntad de las partes.

En la actualidad, doctrina y jurisprudencia reclaman, en términos generales, la concurrencia de ciertos presupuestos básicos para que operen eficazmente los efectos consecuentes al pacto novatorio.

Los requisitos antecedentes, basados también en la necesaria existencia de una obligación válida y preexistente, son los siguientes:

a) Voluntad o intención común de ambas partes - expresa o tácita- de llevar a cabo la extinción de la obligación primitiva o la relevación modificativa del deudor precedente (animus novandi)

b) en defecto de intención novatoria, que la pervivencia simultánea de ambas obligaciones resulte incompatible y, por último ${ }^{6}$,

${ }^{3}$ Este aliquid novi, es el requisito ineludible que exige una diferencia entre la obligación nueva y la precedente. Novedad que puede afectar a alguno de los elementos estructurales de la obligatio, por lo que bien podía consistir en un cambio de deudor, de acreedor, de causa o función o incluso de sus modalidades como, por ejemplo, el término. En este sentido, DíEz-PicAzo afirma «este aliquid novum no debe ser capaz para destruir la identidad de la deuda». El idem creditum es un elemento integrante de la novación clásica, implica que la nueva obligación tiene que tener por objeto el mismo débito que la anterior (vid., Fundamentos del Derecho civil patrimonial, II, Las relaciones obligatorias, Madrid, 1996, pág. 796).

${ }^{4} \mathrm{La}$ identidad en la deuda o promesa pecuniaria se reviste de una forma vinculante que es la estipulación novatoria y afectaba inicial y exclusivamente, a las obligaciones civiles (vid., Fuenteseca DegENEFFe, El problema de la relación entre novatio y delegatio desde Roma hasta las codificaciones europeas, Madrid, 2000, págs. 23, nt. 13 y 33 ).

${ }^{5}$ En este sentido, declara la Sentencia del Tribunal Supremo de 17 de abril de 1979, «es de todo punto improcedente hablar de novación extintiva y aun de la simplemente modificativa cuando falta el segundo concierto de voluntades dando nacimiento a la nueva obligación con animus novandi, o bien de mera alteración permaneciendo el vínculo primitivo».

${ }^{6}$ Dice la Sentencia del Tribunal Supremo de 14 de abril de 1980, «son elementos necesarios para que la novación se produzca, una obligación preexistente, la creación de otra nueva, la disparidad entre ambas y la voluntad de llevar a cabo la sustitución o el animus novandi». 
c) aliquid novi, teniendo en cuenta que de conformidad a la doctrina jurisprudencial, el cambio de sujeto pasivo no implica necesariamente la extinción de la relación precedente ${ }^{7}$.

\section{EL OBJETO DE LA EXPROMISSIO: ÁMBITO DE ACTUACIÓN DEL ACUERDO DE SUSTITUCIÓN PASIVA}

De lo dicho se sigue que podamos afirmar que el requisito o presupuesto preliminar para la concurrencia de la novación, es la preexistencia de una obligación válida ya que, en buena lógica, si se intenta operar algún cambio habrá de tener materialidad esta relación precedente.

Por tanto, teniendo presente que el objeto del acuerdo expromisorio serán las deudas y obligaciones y que, con ello, se pretende la transmisión pasiva en la obligación de hacer y de dar e, incluso, las de no hacer, en las líneas siguientes se ventilará en primer lugar qué tipo de relaciones pueden ser modificadas para, después, analizar el contenido de las relaciones susceptibles de válida alteración.

\section{Las obligaciones susceptibles de ser modificadas o extinguidas: examen de su evolución histórica}

La delimitación del ámbito de actuación de la expromissio, pretende determinar sobre qué tipo de relaciones obligatorias puede operar la figura ${ }^{8}$; en suma, si esta asunción espontánea de deuda del artículo 1.205 del Código civil es un acuerdo capaz de actuar sobre

${ }^{7}$ En definitiva, como asevera la Sentencia del Tribunal Supremo de 24 de febrero de 1984, «faltan los presupuestos precisos para generar aspectos derivados de novación, toda vez que ésta, por su propia naturaleza, tiene su razón de ser en una obligación creada originariamente con posterior proyección a otra, con los esenciales requisitos de obligación preexistente, creación de otra nueva, disparidad entre ambas y voluntad de llevar a cabo la sustitución, lo que no se da en el caso, establecido en la resolución impugnada, de que la obligación se concertó directamente en los términos a que afecta, entre las personas que cuestionan sobre ella». Sobre la materia, vid., MoRETÓN SANZ, "Examen crítico de los fundamentos dogmáticos y jurisprudenciales de la expromisión y del artículo 1.205 del Código civil español (La vicenda modificativa, la sucesión singular de las deudas, el programa dela prestación y la aplicabilidad de ciertos principios contractuales)», $A D C, 2008$, págs. 619 a 719.

${ }^{8}$ Om nes res transire in novationem possunt (Ulpiano, D.46.2.2), todas las obligaciones pueden ser objeto de novación, mediando el requisito del animus novandi. 
cualquier tipo de vínculo o, si antes bien, se circunscribe a las obligaciones que encuentran su origen en un contrato ${ }^{9}$.

Dicha cuestión ha sido tratada, incidentalmente, por la doctrina cuando al sostener la preceptiva extinción de la relación obligatoria por sustitución del elemento pasivo, concluye que su resultado es, de modo invariable, una obligación de naturaleza contractual ${ }^{10}$.

Lo cierto es que dicha inferencia, si se utiliza para concretar la naturaleza de un cambio determinado por una norma, puede ponerse en entredicho dada la existencia de asunciones forzosas o cambios de obligaciones constituidas ope legis. En este punto, la norma sería el cauce de la asunción, si bien no necesariamente desnaturaliza la esencia del acuerdo de asunción que es distinta de la fuente de la obligación resultante.

En buena lógica, quienes aprecien que la novación siempre presenta consecuencias extintivas, sostendrán que la naturaleza de la relación obligatoria sustituyente será la de la fuente novatoria. Empero, si por el contrario, estimamos que las consecuencias del cambio bien puedan ser meramente modificativas, qué duda cabe que tanto la propia relación donde ha sido relevado el sujeto pasivo, como su naturaleza originaria, subsisten independientemente de la vía utilizada para la liberación pasiva. En suma, la peculiaridad de la expromisión es su nota característica residenciada en la espontaneidad del tercero que asume la deuda de otro. Espontaneidad, que no liberalidad o beneficencia. Por tanto, resulta esencial en la expromisión el componente volitivo.

En el sistema romano, en principio, nada impedía afirmar que novables eran todas obligaciones civiles ${ }^{11}$. Por su parte, y como apre-

${ }^{9}$ En este sentido SANCHO REBULLIDA afirmaba que «el concepto de novación es referible a toda obligación, pero no parece, en cambio, referida al concepto de contrato, sino en cuanto se considere una elipsis para designar la relación obligatoria nacida del contrato» [vid., "Comentario a los artículos 1.203 al 1.213», Comentarios al Código civil y Compilaciones forales, XVI, 1, Albaladejo y Díaz Alabart (Dirs.), Madrid, 1991, pág. 607].

${ }^{10}$ Mazeaud, Mazeaud y Chabas sostienen en este punto que, además de nacer por efecto de la novación una obligación nueva que se encontrará sometida a la prescripción específica, la obligación será siempre contractual ya que resulta de la voluntad de las partes «cette obligation est toujours contractuelle, puisqu'elle résulte de la volonté des parties à la novation» (Leçons de Droit civil, II-I, obligations, Paris, 1998, $9^{a}$ ed., pág. 1.250).

${ }^{11}$ Como se expone en el capítulo segundo «El proceso codificador español: proyectos y antecedentes», serán tanto la nacida de un legatum per damnationem; como la futura; la condicional, así como la sometida a término inicial (vid., MORETón SANZ, La asunción espontánea de deuda, cit.). 
ciación sustancial frente a la indefinición romana, Domat estimaba que la novación podría actuar sobre cualquier tipo de obligación por lo que, en definitiva, cualquier deuda podría ser innovada ${ }^{12}$ afirmación compartida por POTHIER ${ }^{13}$.

Si seguimos con la verificación histórica de la presencia de esta novabilidad de las relaciones obligatorias, ya en la época codificadora civil y mercantil en España la materia estaba afectada por novedades y contradicciones doctrinales y legislativas. En este sentido, en el texto de 1821 en su título VI de los Contratos y, en particular, sobre Los modos de disolver parece que limita la novación a las relaciones contractuales ${ }^{14}$; pocos años después, en 1829 tanto la doctrina encarnada en ÁlvAREZ ${ }^{15}$ como el propio Código de comercio, se inclinan por la limitación de la extinción novatoria a las relaciones obligatorias que hayan nacido de contrato ${ }^{16}$. GoRósABEL señala que dichas tesis reduccionistas han de ser corregidas y que, en definitiva, debe operar sobre cualquier tipo de relación obligatoria ${ }^{17}$.

Por su parte, en el mencionado Código de comercio de 1829, su artículo 263 decía: «Las obligaciones mercantiles se estinguen por los modos prescritos en el derecho comun sobre los contratos en general, salvas las disposiciones especiales, que para casos determinados se dan en este Código ${ }^{18}$. De su tenor se aprecia que el ámbito de aplicación de dichas causas se refiere, única y exclusivamente, a las obligaciones mercantiles -amén la remisión explícita al Derecho común como fuente- . Sobre el ámbito de las obligaciones a las que puede afectar el precepto, supera la indeterminación del Derecho romano, toda vez que circunscribe estos modos de extinguirse a las obligacio-

${ }^{12}$ Vid., Les lois civiles dans leur ordre natural (4.2.6), Paris, 1777, pág. 322.

${ }^{13}$ Vid., Tratado de las obligaciones, Buenos Aires, 1978, págs. 316 y sigs.

${ }^{14}$ Vid., MoRetón Sanz, op y loc. cit. 126.

15 Vid., Instituciones de Derecho Real de España, II, Madrid, 1829, págs. 125 y

${ }_{16}$ Que en su artículo 263 señala que las obligaciones mercantiles se extinguirán por las causas previstas para la extinción de los contratos, cuestión que renace con la pretendida omisión del Proyecto de 1851 — como antecedente más directo de las vigentes disposiciones en materia de novación- $\mathrm{y}$, de otra, en el articulado correspondiente a la contratación mercantil.

${ }^{17}$ Vid., Examen de los Principios de Derecho civil español, Tolosa, 1834, págs. 115 y 116.

${ }^{18}$ La doctrina mercantilista de la época daba cuenta de los mecanismos extintivos: éstos, además del pago, eran el ofrecimiento y consignación, compensación, confusión, novación, mutuo disenso, remisión, caso fortuito, prescripción y causas o motivos de rescisión (vid., MARTí DE EIXALÁ, Instituciones del Derecho mercantil de España, Barcelona, 1870, pág. 547). 
nes mercantiles — carácter atribuido en función del sujeto que las ejecuta u objetivamente en otros supuestos-. También consta una cuestión de estilo que no es otra que la recurrente intercambiabilidad del sustantivo contrato por el de obligación. En todo caso, se limita a determinar las vías extintivas de obligaciones nacidas de contrato tal y como acredita su ubicación sistemática y la intitulación del Libro en que está inserta De los contratos del comercio en general, sus formas y efectos. Seguidamente este Código de SAínz DE ANDINo fue derogado por el todavía vigente Código de comercio de $1885^{19}$, donde su artículo 50 prevé las vías de extinción de los contratos de comer$\mathrm{cio}^{20}$ en similares términos a los contemplados por su inmediato antecedente. Por tanto, en el punto relativo a las fórmulas extintivas, coinciden ambos textos codificados ${ }^{21}$.

Como se dice, esta imperfección técnica y la confusión e intercambiabilidad entre relación obligatoria y contrato ha acompañado a la historia codificadora hasta el propio texto codificado, pese a la Enmienda presentada por CoMAS $^{22}$ al Senado.

${ }^{19}$ Como es sabido, el Código de comercio de 1885 carecía de una cláusula derogatoria, por lo que dejó en vigor el de Saínz de Andino (vid., Álvarez Vigaray, «Proyectos del Código civil en la primera mitad del siglo XIX», Anales, RALJ, 19, 1988, pág. 146); lo cierto es que tampoco contiene un elenco de las fuentes de las obligaciones mercantiles.

${ }^{20}$ El Título IV dedicado a las disposiciones generales sobre los contratos de comercio, se abre con el artículo 50 cuyo tenor literal es: «Los contratos mercantiles, en todo lo relativo a sus requisitos, modificaciones, excepciones, interpretación y extinción y a la capacidad de los contratantes, se regirán en todo lo que no se halle expresamente establecido en este Código o en Leyes especiales por las reglas generales del Derecho común».

${ }^{21}$ GÓmEz CALERO, declara que a falta de otra disposición expresa serán las contempladas por el artículo 1.089 del Código civil (vid., «Las obligaciones mercantiles», De-

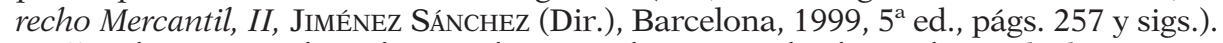

${ }^{22}$ Vid., Proyecto de Código Civil: enmienda presentada al Senado, Madrid, 1885, pág. 33. Por su parte, NAVARRO AMANDI sostiene que si bien la novación y pese a ser una causa de extinción de las obligaciones, resulta hábil para operar sobre las obligaciones contractuales (vid., Código civil de España, Madrid, 1880, pág. 64). Antes, en 1837, TAPIA en su Febrero novísimo, también se limita a los contratos (vid., capítulo 28); FERNÁNDEZ DE LA Hoz, en 1843 también se refiere sólo a los contratos (vid., artículo 1045, nt. 291); GaRCía GoYena, en 1844, tanto en su Febrero reformadísimo como en el artículo 1.134 de su Proyecto de 1851. En especial, este precepto adolecía de la cicatera reducción de los efectos de la novatio a los contratos ( «Hay novación de contrato cuando las partes en él interesadas lo alteran, sujetándolo a distintas condiciones o plazos, sustituyendo una nueva deuda a la antigua, o persona distinta en lugar de la que antes era deudor, o haciendo cualquier otra alteración sustancial que demuestre claramente la intención de novar. Cuando la sustitución de un nuevo deudor se hace por el primitivo, se llama delegación»). Cuestión que se vería reproducida por el todavía vigente Código de comercio de 1885, en su artículo 50, en sede de extinción de los contratos. 
Por cuanto se refiere al vigente Código, su artículo 1.156 despeja ciertas dudas y deficiencias del proceso codificador. El precepto menciona a la novatio como una de las fórmulas por la que se extinguen las obligaciones en general y no sólo los contratos, evitando por fin la persistente imprecisión de los primeros textos ${ }^{23}$. Pese a todo, subsisten algunos supuestos en los que se intercambian ambas denominaciones, obligación y contrato, tal y como sucede en el artículo 1.105, al declarar que «fuera de los casos expresamente mencionados en la ley, y de los en que así lo declare la obligación, nadie responderá de aquellos sucesos que no hubieran podido preverse, o que, previstos, fueran inevitables ${ }^{24}$.

Cuestión diversa será la vía elegida — contractual o no- para modificar una relación obligatoria nacida de una fuente distinta a la contractual, ya que se defiende que, en particular, el acuerdo expromisorio puede operar sobre cualquier relación obligatoria independientemente de su origen ${ }^{25}$.

${ }^{23}$ Parece, por tanto, que este error común fue arrastrado del que a su vez cometiera FERNÁNDEZ DE LA Hoz en su Proyecto privado de Código. En su cuarto y último libro sobre las obligaciones descansa, probablemente, la fuente del criticado reduccionismo imputado a GARCÍA GOYENA, al limitar la extinción novatoria a la categoría contractual. Estos dos datos (uno, la sistemática y dos, la perpetuación del error) ponen de manifiesto, cuando menos, cierta asimilación entre los proyectos privados de codificación y los "públicos» (Código Civil. Redactado con arreglo a la legislación vigente, Madrid, 1843). En todo caso, en el segundo y tercer capítulos de la monografía, se da cuenta de otros antecedentes, como el Proyecto de 1821 e incluso, en la literatura jurídica previa a la codificación (vid., MORETón SANZ, La asunción espontánea de deuda, Valladolid, Lex Nova, 2008, págs. 85 y sigs.). ÁLVAREZ, al desarrollar el Título XXXI lo intitula «De los modos de desatarse las obligaciones», si bien a renglón seguido, enumera «los modos comunes de disolverse los contratos». Al seguir las líneas posteriores se detecta que obligación y contrato fueron empleados, cuando menos, como intercambiables. El primer modo de disolver «los contratos» es la solución o paga, y en el párrafo inmediatamente posterior se dice «el primer modo de quitarse cualquiera obligacion es la solucion ó paga» (Instituciones de Derecho Real de España, II, cit., págs. 125 y 126 respectivamente).

${ }^{24}$ Díez-Picazo, Fundamentos del Derecho Civil Patrimonial. II, cit., pág. 50.

${ }^{25} \mathrm{Vid}$., SANCho Rebullida que sostiene que «no es necesario que la obligación preexistente sea contractual; puede novarse "contractualmente" una obligación nacida de cuasi-contrato o de acto ilícito». Asimismo recoge la Sentencia del Tribunal Supremo de 15 de noviembre 1899 que alude incidentalmente a la posibilidad de novar «las obligaciones declaradas judicialmente» (La novación de las obligaciones, cit., págs. 340 y 341). 


\section{La sustitución del sujeto pasivo en las relaciones obligatorias: la capacidad de las obligaciones para ser modificadas independientemente de la fuente de la que procedan}

\section{A) Las obligaciones jurídico-privadas como relaciones modificables}

En principio, el cambio de deudor vía artículo 1.205 del Código civil puede actuar sobre cualquier obligación jurídico-privada, sea cual fuere su fuente y sea pura o no ${ }^{26}$. De conformidad con este entendimiento, para alterar el lado pasivo de una relación obligatoria resulta preceptiva la existencia de una obligación en sî́27, no que la obligación sea contractual. De modo que la expromissio podría actuar sobre cualquier vínculo obligacional, independientemente del acto jurídico que haya dado lugar al nacimiento de la relación ${ }^{28}$.

${ }^{26}$ Teniendo en cuenta las especialidades de la expromisión condicionada y la posibilidad de operar sobre una relación obligatoria sometida a condición.

${ }^{27}$ Entendido éste como requerimiento preliminar, al margen de otras exigencias imprescindibles para que pueda surtir efectos.

${ }^{28}$ Cuestión distinta es la naturaleza del pacto, acuerdo o acto que produce como efecto principal una sustitución del lado pasivo de una relación; de hecho existe un amplio abanico de alteraciones pasivas constituidas por ley. Subrogaciones forzosas de deudas legales son aquellas en que el Estado asume las deudas de los entes y empresas del sector público estatal; en estos supuestos el régimen jurídico se escapa del Derecho civil, que viene determinado por la norma habilitante del mecanismo de subrogación de deuda. Es el caso prevenido en el Real-Decreto Ley 12/1995, de 28 de diciembre, de Medidas urgentes en materia presupuestaria, tributaria y financiera. En el artículo 9 se contempla la asunción por el Estado, de las deudas de las Sociedades participadas por la Agencia Industrial del Estado. La especialidad de su régimen se singulariza en la innecesariedad del consentimiento de los acreedores que se obvia, y que por el principio de legalidad habrán de aquietarse. Otro caso de transmisiones pasivas de carácter legal, es el que ventiló la Sentencia del Tribunal Supremo de 18 de mayo de 1998, sobre asunción por el Instituto Nacional de Reforma y Desarrollo Agrario (IRYDA) del pago de ciertas obligaciones; o también el previsto en el Real-Decreto Ley 7/1985, de 27 de diciembre, de Subrogación en la deuda de la «Sociedad Española de Automóviles de Turismo, SA» (sobre la subrogación del Estado en las deudas, vid., SANTIAS VIADA, «Asunción por el Estado de deudas de organismo autónomo. Dictamen de la Dirección General de lo Contencioso del Estado de 27 de septiembre de 1976», Presupuesto y Gasto público, 1980, 5). En el ámbito sometido al Derecho privado, encontramos varios supuestos en los que, en defecto de otro régimen, el donatario ha de asumir las deudas; es decir, el cambio de deudor en este caso se opera en virtud del acto pseudoliberal, siendo la ley la que determina quién ha de pagar las prestaciones sin ejecutar. Así sucede en los artículos 642 y 643, preceptos ambos en que como advierte el Prof. AlbaladeJo, «la carga es pagar deudas del donante, no asumirlas ni reembolsarle lo que él haya pagado», a su juicio, del tenor literal sólo se 
A su vez, la fuente de la que dimana la relación en que se sustituye y libera el deudor puede derivar de la ley, de un contrato y cuasicontrato ${ }^{29}$, así como de ciertos actos y omisiones generadoras de responsabilidad civil ${ }^{30}$.

Por otra parte, la jurisprudencia, sensu contrario, ha reconocido que la Ley puede imponer la transmisión del pasivo a quien haya asumido la posición del deudor primitivo en un contrato cuyo origen sea precisamente la propia norma. En este sentido se pronuncia la Sentencia del Tribunal Supremo, de 4 de mayo de $2005^{31}$ que casa la resolución que, a su vez, había impuesto al segundo adquirente de un inmueble los honorarios del arquitecto que realizó el proyecto de obra para el primer dueño. Los términos son «el motivo se estima porque efectivamente no existe precepto legal en la citada Ley $2 / 1974$, de Colegios Profesionales, que permita imponer a la sociedad que no ha sido parte en el contrato con el arquitecto la obligación de pagarle sus honorarios o garantizar el cobro de los mismos. La regulación legal de los Colegios Profesionales tiene un indudable aspecto de interés público por cuanto los servicios de sus colegiados afectan al mismo, pero no lo hay cuando se trata de cuestiones sobre el cobro de honorarios de los colegiados». Y en este caso, la sociedad adquirente no era parte, ya que la adquisición por la Caja adjudicataria de la propiedad de los bienes ejecutados no lleva consigo la subrogación ex lege de la posición del ejecutado en los contratos que hubiese concertado con anterioridad para la construcción.

Por tanto, como estableció la Sentencia del Tribunal Supremo de 5 de marzo de 1965, «tanto la doctrina tradicional española como la

puede desprender que tiene la obligación de pagar y no la de asumir las deudas por eso señala «tampoco lo que ocurre es que se produzca una asunción de la deuda del donante por el donatario. Lo que es inexacto, se entienda como cambio de deudor, que no es posible sin que el acreedor lo acepte, o se entienda como asunción cumulativa, pues de la ley no se deduce que pase el donatario a ser deudor, además de que lo siga siendo el donante» (Albaladejo García, "Comentarios a los artículos 642 y 643», en Comentario del Código Civil, I, cit., págs. 1.628 y sigs.).

${ }^{29}$ Abstracción hecha de su defectuosa adscripción a la categoría de las fuentes, cabe expresamente la delegación total o parcial de la gestión oficiosa, o la sucesión definitiva del gestor por el sustituto, tal y como contempla el artículo 1.890 al decir: «Si el gestor delegare en otra persona todos o algunos de los deberes de su cargo, responderá de los actos del delegado, sin perjuicio de la obligación directa de éste para con el propietario del negocio» (sobre la gestión vid., CUADRADo IGLESIAS, «Aproximación histórica a la gestión oficiosa de negocios ajenos», Estudios de Derecho civil en homenaje al Prof. LACRUZ BERDEJO, 2, 1993, págs. 1.119 a 1.220).

${ }^{30}$ Sobre este extremo DomAT ya había resuelto que toda obligación era hábil para ser novada (vid., Les loix civiles, cit., pág. 322).

${ }^{31}$ Siendo ponente Gullón Ballesteros. 
jurisprudencia de esta Sala, reconoce, al interpretar el artículo 1.203 del Código civil, que éste admite, al lado de la figura tradicional de la novación extintiva, la modificación convencional de las obligaciones, integrante de la llamada novación impropia o modificativa, produciendo la primera como principal efecto la extinción de la obligación primitiva, acompañada de la creación de otra nueva, mientras que la segunda se limita a la simple modificación del vínculo que perdura, aunque modificado, con nuevo contenido y para que se produzca uno y otro es necesario que conste de una manera clara e inequívoca la voluntad de otorgarla bien por manifestación expresa de dicha voluntad, o por exteriorización tácita, deducida sólo de la incompatibilidad entre las dos convenciones, cual dice el artículo 1204 del Código civil, y fuera de este caso es doctrina constante de esta Sala, cuya notoriedad hace innecesaria su cita detallada, que la novación nunca se presume porque supone una renuncia de derechos - hasta el punto que más que modo de extinción de la obligación, lo es de modificación o transformación de ésta- y esa renuncia ha de ser expresa y revelada, bien por términos inequívocos de la voluntad de las partes, o por la creación de otra obligación incompatible con la primera, voluntad que se ha de poner también de manifiesto en la novación modificativa, pues las condiciones se pactan por los contratantes y no por uno solo de ellos y el deudor no puede obligar a su acreedor a que reciba prestación diferente de la pactada, ni en las obligaciones de hacer, puede sustituirse un hecho por otro contra la voluntad del acreedor, cual prescribe el artículo 1166 del Código civil ${ }^{32}$.

De modo que, observando los límites legales mencionados y los requisitos enumerados por la anterior Sentencia de 1965, se podrá asumir la totalidad de las obligaciones dimanantes de cualquier fuente de relaciones como de entre ellas. Este es el caso que ventila la Sentencia del Tribunal Supremo de 30 de diciembre de 1994, donde se

${ }^{32}$ Concluye la resolución advirtiendo «que las cuestiones relativas a la existencia de los hechos determinantes de la novación, son facultad propia y peculiar de la Sala sentenciadora, a cuyo criterio hay que estar en tanto no sea adecuadamente impugnado (sentencias de 9 de abril de 1957 y 26 de enero de 1961, entre otras muchas)». A su vez decía la Sentencia del Tribunal Supremo de 20 de marzo de 1947 «si bien la novación, por implicar siempre una renuncia de derechos, ha de ser expresa, y por ello el Tribunal Supremo viene reiteradamente proclamando el principio justo de que no se presume, no es preciso que la voluntad de novar conste de modo terminante en el caso de incompatibilidad entre las dos obligaciones porque si ésta existe de modo manifiesto, tal circunstancia basta para impedir el cumplimiento de la primera». 
asume por un socio la cláusula penal que pesaba como accesoria de la principal ${ }^{33}$.

\section{B) El pacto de intransmisibilidad pasiva}

Cuestión distinta es que las partes, en el ejercicio de su autonomía de la voluntad privada, hayan resuelto de común acuerdo la autoimposición de la intransmisibilidad de una o de todas las obligaciones integradas en una relación obligatoria ${ }^{34}$. De hecho es el supuesto que se ventila en la Sentencia del Tribunal Supremo de 25 de abril de 1975 dado que en la asunción de las obligaciones se había incluido la siguiente cláusula de intransmisibilidad en la que las vendedoras «no tendrán más acción que la persona contra la Sociedad Compradora» de modo que «excluyendo toda eficacia de carácter real que pudiera afectar a tercero y marginando tanto de la operación en sí como su relación con el objeto vendido de las consecuencias del posible incumplimiento». En definitiva, prospera el recurso de casación interpuesto por la Entidad asumente de las obligaciones ya que como «pudo constatar [en el Registro de la Propiedad] que las discutidas obligaciones eran de carácter personal», comprobó la intransmisibilidad de dichas obligaciones pendientes ${ }^{35}$.

${ }^{33}$ Vid., AdAme García, "Comentario a la Sentencia del Tribunal Supremo de 30 de diciembre de 1994», CCC, 38, 1994.

${ }^{34} \mathrm{Vid}$., la Resolución de 16 de marzo de 1981, que aprueba los pliegos generales de condiciones económico-administrativas y técnico-facultativas que habrán de regir necesariamente para la contratación por los Consorcios para la gestión e inspección de las Contribuciones Territoriales, o por las Corporaciones locales, de los trabajos para la formación, conservación y revisión de los Catastros Urbano y Rústico. En su artículo 13, se establece la radical prohibición de la novación subjetiva, en los siguientes términos: "queda absolutamente prohibida la novación subjetiva del contrato, por cesión del mismo a terceros. La subcontratación de trabajos parciales por parte del contratista, sólo es posible si aquélla fue consignada en su momento de manera explícita, bien por referencia a los trabajos, bien, incluso, por consignación del o los subcontratistas en la oferta efectuada al particular en la licitación».

${ }^{35}$ También las obligaciones futuras ya que, por extensión, como el artículo 1.824 del Código civil advierte para la fianza: «la fianza no puede existir sin una obligación válida.- Puede, no obstante, recaer sobre una obligación cuya nulidad pueda ser reclamada a virtud de una excepción puramente personal del obligado, como la de la menor edad.- Exceptúase de la disposición del párrafo anterior el caso de préstamo hecho al hijo de familia». Y sigue el artículo 1.825 declarando "puede también prestarse fianza en garantía de deudas futuras, cuyo importe no sea aún conocido; pero no se podrá reclamar contra el fiador hasta que la deuda sea líquida». En este sentido y sobre la fianza de cosa futura, vid., la Sentencia del Tribunal Supremo de 13 de octubre de 2005. 
C) El caso de la obligación natural como relación obligatoria en que puede ser sustituido el deudor originario

En los estudios romanísticos, en general, se afirma que la posibilidad de novar una obligación natural no es sino una interpolación y sólo y con dicho valor ha de ser interpretada ${ }^{36}$. Por otra parte también es cierto que, a su vez, el análisis de la susceptibilidad de novar una relación de aquella naturaleza exige, del mismo modo, la revisión y actualización de su concepto actual, ya que la noción jurisprudencial y doctrinal de la figura no es idéntica a la que se deduce de aquel entendimiento original. Cuestión a la que se añade que, por extensión según LACRUZ BERDEJO-SANCHO REBULLIDA, al igual que cabe la novación de una obligación natural, resulta también posible garantizar una obligación de este tipo mediante prenda o fianza ${ }^{37}$.

El tratamiento recibido por las obligaciones naturales en el Derecho común comprendía un número determinado de obligaciones que carecían de acción y por eso podían ser novadas o garantizadas ${ }^{38}$. Por su parte, el Fuero nuevo navarro, en un entendimiento mixto como deber moral y obligación irrepetible, reconoce la totalidad de efectos civiles a la novación practicada sobre una obligación natural ${ }^{39}$.

En todo caso, al margen de las cuestiones debatidas en el seno del Derecho romano, se ha de tener en cuenta que, aceptada por el Tribunal Supremo la exigibilidad de las relaciones que tengan origen en un deber moral de carácter patrimonial, debidamente comunicadas al

${ }^{36} \mathrm{Vid}$., Fuenteseca DegenefFe, op. cit., págs. 27 y 23 y Fuenteseca Díaz, «Recensión a BONIFACIO», AHDE, 1950, pág. 914; BONFANTE, "Le obbligazioni naturali e il debito di giuoco», Scritti giuridici varii, III. Obbligazioni, comunione e possesso, Milano, 1921, págs. 40 a 103; GaLLI, Conversión de las obligaciones naturales en obligaciones civiles, Buenos Aires, 1942; BIONDI, «Ricognizione e novazione di obbligazione naturale», Foro Padano, I, XVI, 4, 1961, págs. 479 a 485; Palazzo, "La novatio di un'obbligazione naturale», Sinossi. Giur., 1986; Delebecoue, «Novation: obligation naturelle en obligation civile (Cass. Com. 31 mayo 1994)», Recueil Dalloz Sirey, 1995, págs. 90 a 91; REALEs EsPina, La obligación natural en el Código Civil, cit.

${ }^{37}$ Vid., Elementos de Derecho civil, II, Derecho de obligaciones, I, cit., pág. 19.

${ }^{38} \mathrm{Vid}$., FuENMAYOR y CHAMPÍN, «El cumplimiento post mortem de las obligaciones naturales», Estudios de Derecho Civil, II, Pamplona, 1992, págs. 1.277 y 1.278, concretamente, el cumplimiento directo e indirecto de las obligaciones; REALES ESPINA, $\mathrm{La}$ obligación natural en el Código civil, Granada, 2000, pág. 19.

${ }^{39}$ La Ley 510 dice que «no será repetible el pago cuando se haya hecho en cumplimiento de un deber moral, o impuesto por el uso, aunque no sea judicialmente exigible. El reconocimiento, la novación, la compensación y la garantía de las obligaciones naturales producen efectos civiles» [vid., Egusouiza BaLMASEDA, «Comentario a la Ley 510», Comentarios al Fuero Nuevo. Compilación del Derecho Civil Foral de Navarra., Rubio ToRRANo (Dir.), Pamplona, 2002, págs. 1.742 a 1.747]. 
beneficiario, qué duda cabe que también éstas podrán ser asumidas por un sujeto distinto al obligado originariamente ${ }^{40}$.

D) La responsabilidad extracontractual como obligación asumible por un tercero ajeno

Como señala la mejor doctrina, las fuentes de las relaciones obligatorias previstas en el Código civil pueden ser reconducidas a las que tengan su origen en la voluntad de las partes frente a las que tengan su origen en la ley ${ }^{41}$. Desde esta perspectiva, y pese a ciertas dudas, las obligaciones extracontractuales son susceptibles de sufrir alteraciones subjetivas. En este sentido y plenamente consecuente con sus planteamientos sobre la naturaleza necesariamente extintiva de la novación y la imposibilidad de transmisión de las deudas, declara SANCHO REBULLIDA que "puesto que el único acto jurídico con virtualidad novatoria es el contrato, cabe afirmar que, así como la obligación preexistente puede ser extracontractual, la nueva obligación tiene que ser necesariamente contractual $»^{42}$. Fundados en estos argumentos, se deduce que ante un cambio tan sustancial se produce necesariamente la extinción de la relación previa y su transformación por una obligación contractual.

Por el contrario, y a mi juicio, que dicho efecto participe del que presente el acuerdo modificativo, no autoriza a que se sostenga que la naturaleza del pacto sea también la de la relación resultante. Resulta en definitiva un argumento tautológico ya que, en suma, se parte de la extinción y no del acuerdo que la produce. En síntesis, dada una relación obligatoria nacida de cualquiera de las fuentes prevenidas en el Código civil, podrá operarse sobre dicha obligación cualquier acuerdo válido, acuerdo cuyo efecto será el mantenimiento de las cualidades y propiedades del contenido de la relación previa. Por tanto, la fuente modificativa no altera la naturaleza de la relación sobre la que opera sino que, al contrario, subsiste alterada en los términos que hayan acordado las partes. Defender lo contrario es sos-

${ }^{40}$ Sobre el estado de la cuestión y la jurisprudencia en materia de obligaciones naturales, por todos, a mi Maestro, el Prof. LASARTE Álvarez, quien evidencia que los perfiles de la obligación natural han sido radicalmente modificados por la doctrina y jurisprudencia contemporáneas, presentando en síntesis una naturaleza distinta de las procedentes nominalmente de Roma (vid., Principios de Derecho Civil, 2, Derecho de obligaciones, Madrid, 2011, 15 a ed., págs. 14 y sigs.).

${ }^{41}$ En este sentido, también por todos, vid., mi Maestro, Lasarte Álvarez, Principios de Derecho Civil, 2, cit., págs. 22 y sigs.

${ }^{42}$ La novación de las obligaciones, Barcelona, 1964, pág. 346. 
tener que cabe la novación de la causa y del sujeto simultáneamente, cuando una alteración tan radical produce sin duda la extinción sin subsiguiente reemplazo por otra.

Una cosa es que el acuerdo suscrito por un tercero y el titular de dicho vínculo presente naturaleza contractual, y otra distinta es afirmar que con el acuerdo contractual se altera la naturaleza extracontractual precedente. Desde luego ha de tenerse en cuenta que la causa de esa asunción de deuda practicada, en nuestro caso recurriendo a un pacto expromisorio, será la de la relación extracontractual. Pero, distinta de la causa del acuerdo expromisorio - que es la asunción de la obligación precedente- es la naturaleza contractual del pacto de asunción; como distinta es la naturaleza del acuerdo asuntivo de los efectos que produce.

Por otra parte, y pese a que no se coincida en los efectos del acuerdo expromisorio y al cambio de naturaleza, sí que compartimos la declarada aptitud de las relaciones extracontractuales para ser asumidas por un tercero. Por lo que se refiere a las obligaciones nacidas de acto ilícito, SANCHo Rebullida sostuvo que «si, como consecuencia de un accidente de circulación, el autor y la víctima, en evitación de litigios, limitan, definen y pactan una indemnización convencional como solución de la responsabilidad nacida del art. 1.902 del Código civil, la indeterminación de ésta no creo la haga insusceptible de novación, lo cual tiene importancia a efectos de relación causal entre ambas: repetibilidad del obligado contra un tercero si se descubre, después, que fue el culpable del accidente» ${ }^{43}$.

En todo caso, la práctica acredita que las obligaciones extracontractuales han sido, y son, objeto de alteraciones, con carácter extintivo o con consecuencias modificativas ${ }^{44}$.

${ }^{43}$ La novación de las obligaciones, cit., págs. 340 y 341. Expresamente se fundan en el 1.205 del Código civil, Soto NiETo, «La responsabilidad civil del médico en la esfera penal», Revista de Responsabilidad Civil, Circulación y Seguro, 1993, 12, 491 a 505, y en la misma Revista de 1996, el artículo de MAESTRO, «Los valores garantizados en el seguro sobre vida». Por otra parte, la hipótesis de la novación de un trato preliminar resulta ciertamente remota.

${ }^{44}$ En este sentido, la Sentencia del Tribunal Supremo de 6 de abril de 1974 ventiló y admitió una novación extintiva de la obligación de resarcir a la víctima de los daños producidos por unas voladuras, hecha en un reconocimiento de deuda, por otra obligación de carácter voluntario. A mayor abundamiento, esta extinción de la primera relación produjo que el plazo para la interposición de las acciones correspondientes pasase del año del que gozan las extracontractuales a los quince años previstos en las que presenten carácter personal. 
Así lo evidencia la jurisprudencia y, en particular, es el supuesto de la Sentencia del Tribunal Supremo de 7 de junio de 1982. En ella se declara, a la vista del documento privado por el que el nuevo adquirente de la finca asume la responsabilidad por los daños causados por las obras del anterior propietario, tanto la posibilidad de asumir modificativamente dicha obligación legal como el hecho de que la acreedora demande al asumente implica su aceptación como nuevo deudor. Así dice: «en los motivos segundo y tercero ambos amparados en el núm. 1 del art. 1.692 de la Ley de Enjuiciamiento, se plantea el único tema de fondo que llega a este trámite, que es el de la novación, respecto de la obligación de indemnizar antes referida a la en su día actora y ahora recurrida por los daños y perjuicios que se le ocasionaron, la cual, contraída por el primitivo propietario de la finca colindante, fue asumida por el actual (que figura como recurrente), denunciando violación, en un caso del art. 1.204 -en relación con el 1.283- y en el otro, del 1.205, todos del Código civil; ninguno de los cuales es tampoco susceptible de estimación, porque es bien sabido que el 1.204 se refiere a la novación propia o extintiva exigiendo 'para que una obligación quede extinguida', el específico animus novandi o que la antigua y la nueva obligación sean de todo punto incompatibles, que no es el supuesto que aquí se contempla, en el que la obligación simplemente se modifica (novación impropia o modificativa), de acuerdo con el número $2^{\circ}$ del artículo 1.203 , es decir 'sustituyendo la persona del deudor' por otro nuevo que asume la obligación (la misma e idéntica obligación) que tenía el anterior, que no requiere aquél animus extintivo, justo porque la obligación no se extingue ${ }^{45}$.

\section{La transmisión de la conducta comprometida: la expromisión en las obligaciones de dar, hacer y no hacer}

A) Límites a la transmisibilidad de la conducta prometida por el deudor

Dada una relación obligatoria válida y eficaz, independientemente de su origen y con el cumplimiento de los requisitos correspondientes, podrá ser objeto de transmisión. Atendiendo al contenido típico de la conducta adeudada ${ }^{46}$, las relaciones que consistan en dar o

${ }^{45}$ Vid., también últ. Sentencia del Tribunal Supremo de 27 de octubre de 2006, siendo Ponente Gullón Ballesteros.

${ }^{46}$ Dice el artículo 1.088 del Código civil: «Toda obligación consiste en dar, hacer o no hacer alguna cosa». 
entregar alguna cosa, presentarán el límite de su disponibilidad por parte de quien pretende asumir su cumplimiento ${ }^{47}$; en cuanto a las obligaciones de hacer quedarán también sometidas a la aceptación del acreedor por lo que a la conducta adeudada se refiere. Finalmente, ofrece más resistencias la obligación consistente en una conducta de no hacer ${ }^{48}$.

En todo caso, y como señala mi Maestro, si bien los diversos criterios clasificatorios son, en principio, meramente instrumentales, lo cierto es que también evidencian el régimen jurídico propio ${ }^{49}$. En su virtud, conviene reiterar que la relación obligatoria susceptible de ser transmitida es la no instantánea. Nos remitimos, también, al análisis del artículo 1.207 para el estudio de la transmisibilidad de las relaciones accesorias ${ }^{50}$; así como al del artículo 1.143 para el caso de que un tercero pretenda asumir una deuda con pluralidad de sujetos organizados de forma solidaria o mancomunada. En cuanto a las obligaciones divisibles, sabido es que «la divisibilidad natural de la prestación en sí misma considerada no autoriza el cumplimiento parcial de la obligación, que por ser considerado perjudicial para el acreedor, sólo es admitido cuando así se haya pactado o establecido en el título constitutivo de la obligación, conforme al principio establecido en el artículo 1.169 del Código civil»» ${ }^{51}$, argumento que, por extensión, cabe aplicar a su sucesión pasiva.

${ }^{47}$ Con claridad y referido a la intervención en la deuda ajena, sostiene HERNÁNDEZ MORENO «en cuanto a la prestación objeto de la obligación, es decir, en cuanto a los límites objetivos a la intervención de terceros en la relación jurídico-obligatoria ajena, la gestión de éstos solamente encuentra como obstáculos: en las obligaciones de dar, la libre disposición y la capacidad para enajenar la cosa debida, tal y como exige la norma del art. 1.160 del Código. Y en las obligaciones de hacer, la calidad y circunstancias de la persona elegida por el acreedor (cfr. el art. 1.161 C.c.), fuera de esos límites (importantes pero en modo alguno excluyentes) la prestación del tercero es idénticamente posible a la del deudor»(El pago del tercero, cit., pág. 4).

${ }^{48}$ Sobre las obligaciones de dar, hacer y no hacer, vid., DíEz-Picazo, Fundamentos del Derecho civil patrimonial, II, cit., pág. 481.

${ }^{49}$ Vid., Lasarte Álvarez, Curso de Derecho civil patrimonial. Introducción al Derecho, Madrid, $13^{\mathrm{a}}$ ed., pág. 413.

${ }^{50}$ Vid., Moretón SANZ, «Examen crítico de los fundamentos dogmáticos y jurisprudenciales de la expromisión y del artículo del Código civil español (La vicenda modificativa, la sucesión singular de las deudas, el programa de la prestación y la aplicabilidad de ciertos principios contractuales)», cit.

${ }^{51}$ Lasarte Álvarez, Principios de Derecho civil, 2, Derecho de obligaciones, cit., pág. 66. El artículo 1.169 dice: "a menos que el contrato expresamente lo autorice, no podrá compelerse al acreedor a recibir parcialmente las prestaciones en que consista la obligación». 
B) El caso de las obligaciones negativas: la conducta omisiva del deudor como obligación transmisible

Las obligaciones negativas se caracterizan, entre otros aspectos, por su patrimonialidad, su pretendida indivisibilidad y su discutido personalismo, extremo éste que según cierto sector, las hace intransmisibles tanto inter vivos como mortis causa ${ }^{52}$. En su virtud, parte de la doctrina declara la intransmisibilidad de las obligaciones negativas ya «que no es posible que un tercero lleve a cabo la actividad solutoria de una prestación negativa porque las actuaciones del deudor son insustituibles ${ }^{53}$. Otra corriente más flexible estima que, salvo óbice, resultarán de aplicación las reglas ordinarias relativas al cambio en la posición deudora ${ }^{54}$, si bien no ocultan las dificultades prácticas de esta posibilidad dogmática ${ }^{55}$.

De lo dicho se sigue que «puede percibirse que de las figuras señaladas, que suponen una modificación subjetiva en la persona del deudor, la de más difícil concurrencia en materia de obligaciones negativas será la del convenio expromisorio entre acreedor primitivo y

${ }^{52}$ Vid., Coviello, L'obbligazione negativa, Napoli, 1939, págs. 60 y sigs.

${ }^{53} \mathrm{Vid}$., Egusouiza Balmaseda, La configuración jurídica de las obligaciones negativas, Barcelona, 1990. En su tesis sobre la «Configuración jurídica de las obligaciones negativas», dirigida por RUBIo TORRANO (leída en la Universidad de La Laguna en 1988, publicada en Barcelona en 1990 con el mismo título, págs. 134 y 135).

${ }^{54}$ Las obligaciones de dar (entrega, traslado posesorio, traspaso); de hacer, que salvo las personalísimas, aceptan el pago del tercero (obligaciones de medios y de resultado) y las de no hacer. En este sentido resulta posible idear la hipótesis de las obligaciones de dar personalísimas y personalísimas de no hacer (vid., LASARTE ÁlvAREZ, Principios de Derecho civil, 2, cit., pág. 57). Díez-Picazo, en función del distinto régimen jurídico aplicable, diferencia a las obligaciones en «que el interés del acreedor quede satisfecho cuando la actividad sea llevada a cabo en su favor, quienes quiera que sean las personas que la realicen, o que el interés sólo pueda quedar satisfecho por la persona que realice la actividad comprometida, que ha de ser el propio deudor». El primero de los casos, autorizaría a hablar de la fungibilidad de la prestación, toda vez que la actividad resulta sustituible e intercambiable. Las infungibles, por el contrario, se caracterizan por exigir que la actividad sea cumplida única y exclusivamente por el deudor de la prestación, resultando «la persona que ha de prestar su actividad constituye un elemento esencial del programa de prestación y no puede por ello ser sustituida por otra. El comportamiento debido se llama en estos casos personal o 'personalísimo'» (Fundamentos del Derecho civil patrimonial, II, cit., pág. 244).

${ }^{55} \mathrm{Vid}$., el caso recogido por Mazeaud del adquirente de un fondo de comercio y la cláusula de no competir suscrita a favor del vendedor, «así, cuando un comerciante ha tomado, frente al propietario de un fondo de comercio, un compromiso de no competir, los tribunales permiten al adquirente del establecimiento, causahabiente singular de su vendedor, exigir el cumplimiento de la promesa hecha al vendedor: Req., 18 de mayo de 1868" (Lecciones de Derecho Civil. Parte segunda, Volumen III, Cumplimiento, extinción y transmisión de las obligaciones, Buenos Aires, 1960, pág. 55). 
tercero (nuevo deudor) sin conocimiento del deudor de la omisión» ${ }^{56}$.

Con todo y en lo que se refiere a las vicisitudes y modificaciones de la obligación negativa y, en particular acerca del potencial cambio de deudor, en opinión de otra corriente doctrinal se admite sin dificultad el convenio expromisorio ${ }^{57}$, añadiéndose —más dudosamente a nuestro juicio- que sin la necesaria concurrencia del consentimiento o ratificación del acreedor ${ }^{58}$.

En cuanto a la supuesta intransmisibilidad de las obligaciones negativas, ciertos problemas del ejemplo propuesto por IHERING —en el señero caso del subarriendo de vivienda con un piano, el subarrendatario sucede al arrendatario en la obligación de no tocar el instrumento musical ${ }^{59}$ - , se deducen de su valoración desde la teoría del interés y, en particular, de las posibles consecuencias provocadas por el pretendido valor patrimonial de todas las obligaciones. Finalmente esta teoría es refutada afirmando IHERING que, como juez, no tendría el menor escrúpulo en conceder una indemnización en favor del arrendador por la música que tocan faltando a las condiciones estipuladas ${ }^{60}$. La propia equidad exige entender que habiéndose impuesto en un vecino la obligación legal de insonorizar la vivienda o no tocar el piano en ella dados los daños que causa a los otros copropietarios, dicha obligación deberá ser cumplida por quien ocupe su lugar ${ }^{61}$.

${ }^{56}$ Vid., Ferrer de SAN-SEgundo, La Obligación Negativa, Madrid, 2001, pág. 183.

${ }^{57}$ A favor de su transmisibilidad, Fernández Villa estima posible el cambio de deudor, al menos nominalmente, en todo tipo de relaciones obligatorias sean éstas de dar, de hacer o de no hacer (vid., El pago con subrogación: revisión del artículo 1.212 del Código Civil español, Granada, 1999, pág. 141). En cuanto al aseguramiento de las obligaciones de no hacer vid., ZAMORA SITGES, «El aseguramiento de las obligaciones», $R D P, \mathrm{XXXI}, 360,1947$, pág. 166.

${ }^{58}$ Vid., Ferrer de SAN-Segundo, La Obligación Negativa, cit., págs. 168 a 187.

${ }^{59}$ Este ejemplo de objeto de prestación negativa está extraído de la obra de IHERING, «Del interés en los contratos y de la supuesta necesidad del valor patrimonial de las prestaciones obligatorias», Tres estudios jurídicos, Buenos Aires, 1947, págs. 86 a 159. Vid., también Lacruz Berdejo-Sancho Rebullida, Elementos de Derecho civil, II, Derecho de obligaciones, I, Barcelona, 1985, $2^{\text {a }}$ ed. pág. 56; hace propio el paradigmático supuesto de IHERING, BASOZÁBAL, "El contrato de asunción de deuda», ADC, LIII, I, 2000, pág. 134, nt. 193.

${ }^{60}$ Vid., IHERING, «Del interés en los contratos y de la supuesta necesidad del valor patrimonial de las prestaciones obligatorias», Tres estudios jurídicos, cit., págs. 91 y 92 y 126. Por otra parte, el problema de la ejecución de las obligaciones de no hacer implica que su incumplimiento únicamente pueda ser resarcido en una medida patrimonial así como las propias dificultades de imposición de su cumplimiento (vid., el artículo 710 de la nueva Ley de Enjuiciamiento Civil).

${ }^{61} \mathrm{Vid}$., Sentencia del Juzgado de primera instancia número 10 de los de Bilbao, del 11 de octubre de 2005 (vid., también MORETón SANZ, «La intimidad personal y familiar 
En la regla construida por IHERING, se encuentra algún vago argumento sobre la intransferibilidad de las obligaciones consistentes en una conducta negativa, así «la promesa debe tener un interés para aquel a quien se hace, aunque este interés no sea de naturaleza $p a-$

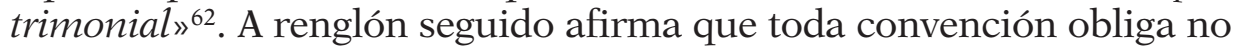
por ser una promesa sino siempre y cuando la restricción impuesta y aceptada por el que promete aproveche a aquel que la recibe. Es "preciso que el uno gane lo que el otro sufra; la simple restricción como tal no encuentra protección jurídica; es preciso que esté motivada y justificada por el interés de otro ${ }^{63}$.

Puede concluirse que en la obligación negativa, si se transmitiese la prestación no se acompañaría del interés, ya que la restricción aceptada por el arrendatario, beneficiaba directamente al arrendador; al transmitirse el derecho arrendaticio, no es posible transmitir al tiempo el interés, ya que la restricción soportada por el subarrendatario, no iría acompañada del condigno aprovechamiento del arrendatario-subarrendador.

Con todo se trata de disquisiciones, a mi juicio, estériles ya que bastará con que el acreedor de dicha prestación negativa acepte el cambio de sujeto pasivo para que así sea exigible y observable por quien haya ocupado el lugar de otro. Y si, habiéndose aceptado por el titular del derecho de crédito el cambio de sujeto pasivo el antiguo incumpliese, es decir, incurriese en la conducta vedada, las consecuencias indemnizatorias del incumplimiento recaerán en el nuevo deudor.

Por fin, la transmisibilidad en las obligaciones de resultado y de medios - caracterizadas desde la perspectiva del tipo de conductaresulta más que posible en la primera de ellas, si bien en las segundas al concursar la lex artis, se dificulta la libre cesión de las obligaciones toda vez que están presididas por un acusada nota personalista ${ }^{64}$. Con todo, nuevamente, hace acto de presencia el contenido del artículo del 1.205 del Código civil, por lo que si el acreedor consiente resultará posible incluso en éstas últimas sustituir al sujeto comprometido.

a la luz de la Jurisprudencia del TEDH: el caso español y la protección contra las inmisiones derivadas de la contaminación acústica», Revista Jurídica U.I.P.R.,XLI, 2006, pág. 304, nt. 15).

${ }^{62}$ IHERING, op. cit., pág. 129.

${ }^{63}$ Ibidem.

${ }^{64}$ Excede de las pretensiones de este trabajo, si bien basta como apunte, el sistema de venias que requiere siempre o un mandato verbal o una autorización para la subrogación de funciones. 
C) Cambio de deudor en las obligaciones bilaterales y unilaterales

Si nos centramos ahora en particular en la clasificación de los contratos en función del nacimiento de obligaciones a cargo de una o de ambas partes, ${ }^{65}$ el cambio de deudor puede plantearse tanto en relaciones de un tipo o de otro ${ }^{66}$. Cabe así cuestionar el potencial cambio de deudor en una relación obligatoria de carácter unilateral, toda vez que sujeto pasivo resultará ser el donante; en el contrato de mandato, el mandatario y en el de depósito, el depositante. $\mathrm{O}$ el prestatario que es el único que queda obligado a reintegrar el importe recibido en el contrato de préstamo sin interés o mutuo. En principio, nada se opone a ello, antes bien y al contrario, refuerza la tesis defendida.

Por otra parte, cabe el cambio de deudor en las relaciones obligatorias de carácter bilateral ${ }^{67}$, específicamente en el contrato que persiga una finalidad de esta especie. En principio, el deudor podrá verse sustituido en su conducta comprometida por un tercero si lo acepta el acreedor. Exigirá una revisión de la posibilidad del supuesto en que se produzca, exclusivamente, la liberación de la parte adeudada, con continuidad en la posición activa en cuanto al crédito recíproco ya que, si una parte contractual en la integridad de su derecho-deber de crédito es sustituida por un tercero, la figura atípica de la que se habla es la de cesión de contrato ${ }^{68}$.

Por tanto, en un contrato bilateral los casos posibles serán: el de la parte contractual que ha sido satisfecha por la otra, en cuanto se refiere al derecho de crédito y que aún no ha cumplido sus obligaciones correspectivas y ahí concurre la expromisión; el segundo supuesto sería el de cumplimiento parcial de sus deudas y satisfacción parcial de sus derechos; el caso pretendido de cesión de la posición contractual íntegra, más coincide — como se ha dicho—- con la figura di-

${ }^{65}$ Vid., Lasarte Álvarez, Principios de Derecho civil, 3, Contratos, Madrid, 2010, $13^{\text {a }}$ ed., pág. 16.

${ }^{66}$ En definitiva, y recurriendo a los símiles propios de la escuela organicista, en primer lugar, la materia prima que es el barro sobre el que modelar; si ya hemos dicho que todas las relaciones obligatorias son aptas para su transmisión, habrá de ser evaluada la propia composición del barro. En suma, aquellas que tengan por objeto dar, hacer o la duda sobre las negativas. Por otra parte, distinta de la materia prima (el barro o la obligación) y en segundo lugar, estarán las manos que modelan el barro: es decir, la sustitución pasiva vía contrato o mediante ley.

${ }^{67} \mathrm{La}$ expromisión de un contrato bilateral según ANDREOLI (vid., La cesión del contrato, Madrid, 1956, págs. 22 y 567).

${ }^{68}$ Vid., Moretón Sanz, «La expromisión ante el pago del tercero y la cesión de contrato", Homenaje al Prof. LALAGUNA y RCDI, 2010. 
señada jurisprudencialmente de la cesión de contratos. En síntesis, el acuerdo expromisorio podrá operar sobre una o todas las obligaciones pendientes en un contrato bilateral tal y como puso de manifiesto una vieja Sentencia del Tribunal Supremo de 22 de junio de $1911^{69}$.

El acuerdo expromisorio producirá, por tanto, la entrada de un nuevo deudor que suple al anterior por lo que a las obligaciones que le competían se refiere, con la particularidad, que en los casos de relaciones bilaterales, quien ocupaba la posición de deudor se ve liberado de las obligaciones, perviviendo en el vínculo como titular de los derechos, facultades o prerrogativas les correspondan. En último extremo, una de las partes de la relación puede ser sustituida de sus obligaciones, permaneciendo como titular de sus derechos o situaciones subjetivas de poder ${ }^{70}$.

En suma hipotéticamente cabe la sustitución de las obligaciones —que no de los derechos- en las relaciones bilaterales correspectivas atomizando los derechos de las cargas que se imputaban a una de las partes; caso de que en un contrato bilateral se ceda íntegramente la posición contractual compuesta por derechos y obligaciones estaremos ante el supuesto atípico de la cesión de contrato.

\section{Referencia al cambio de deudor en la denominada novación o modificación de la hipoteca}

Como es sabido, el ámbito en que se desenvuelve la novación es el del Derecho de obligaciones, ya que no cabe admitir la novatio de los derechos reales ${ }^{71}$. Sólo con un valor entendido se acepta que por ex-

${ }^{69}$ Vid., Rimblas Rimblas, Código Civil. Interpretado y anotado, con arreglo a las modificaciones introducidas por la ley de 24 de abril de 1958, Barcelona, 1958, pág. 716; vid., PINo, Il contratto con prestazioni corrispettive. Bilateralità, onerosità e corrispettività nella teoria del contratto, Padova, 1963; Ravà, La bilateralità del Diritto Civile, Milano, 1963. (Separata di Studio in memoria di Tullio Ascarelli). Por su parte, el Maestro ALONSo aclaraba certeramente que «el deudor vinculado al cumplimiento de la obligación en situación de reciprocidad se hace responsable permanentemente hasta el momento en que, voluntaria o forzosamente, realiza el contenido de la prestación» (Sobre la esencia del contrato bilateral, Salamanca, 1967, pág. 46).

${ }^{70}$ Para la noción de la bilateralidad y el cambio de sujetos pasivo, vid., CASTRO Y BRAvo, "Cesión de arrendamiento y subarriendo», RGLJ, LXXIX, 156-II, 1930, págs. 130 a 169.

${ }^{71}$ Vid., en este sentido a LoIs PUENTE cuando declara que «no implica que no pueda modificarse la hipoteca» («Préstamo hipotecario: novación y ampliación. Requisitos. Comentario a la RDRN de 26 de mayo de 2001 », BCG, 244, noviembre, 2001, págs. 2.939 a 2.943); CHICO y ORTIZ, Estudios sobre Derecho Hipotecario I y II, Madrid, 1989, 2ª ed.; VIDAL FRANCÉs, «Dos extrañas cláusulas en la novación y en la 
tensión las causas extintivas del vínculo accesorio sean las de la principal que garantiza.

De modo que, con las cautelas referidas, se puede aplicar el artículo 1.156 del Código civil a los derechos reales de garantía y, en particular, a la hipoteca; en concreto, al extinguirse por novación, en su caso, la obligación garantizada, idéntica suerte correrá la garantía real $^{72}$. Es moneda corriente entre los hipotecaristas prácticos mencionar expresamente la novación de la hipoteca, empleando figuradamente el todo por la parte ${ }^{73}$. Por eso se afirma que, en caso de venta de finca hipotecada, al no caber la novatio del derecho real lo que se nova es el préstamo garantizado con ese derecho de realización del valor. Al fin y al cabo la expromissio se constituye en uno de los fenómenos de vida ${ }^{74}$ de las relaciones obligatorias ${ }^{75}$.

subrogación de hipotecas», Boletín del Colegio de Registradores de España, 33, 43, 1998, págs. 2.989 a 2.993. Para la precisa limitación del ámbito de actuación de la novatio, vid., GutiérRez SANTIAGo, La novación objetiva por el cambio de objeto, Granada, 1999, págs. 123 y 230 y la Resolución de la Dirección General de los Registros y del Notariado, de 17 de enero de 2002, sobre novación de hipoteca consistente en la entrega de una nueva cantidad y ampliación del plazo, con fijación de nueva responsabilidad hipotecaria (vid., también LACRUZ BERDEJo y DíEz-Picazo, Elementos de Derecho

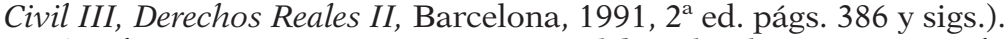

72 Vid., Gómez GÁLligo, "La extinción del crédito hipotecario», Boletín del Centro de Estudios Hipotecarios de Cataluña, 72, 1997, págs. 463 a 542; JoRdano FraGa, «Transmisión del crédito cedido y de la hipoteca accesoria en el régimen vigente de la cesión de créditos hipotecarios», $R C D I$, LXXV, 653, 1999, págs. 1.275 a 1.333.

${ }^{73}$ Sobre la novación de la obligación y de la hipoteca, vid., RDGRN de 27 de noviembre de 1999.

${ }^{74}$ Vid., De Diego, La transmisión de las obligaciones según la doctrina y la legislación española y extranjera (La transmisibilidad de las obligaciones), Madrid, 1912, pág. 32. Esta terminología se asemeja al ciclo vital de la relación expresada por ALLARA y por BETTI, como vicenda y a la teoría del órgano de GIERKE y la vicisitud como ente vivo, como en particular había sido expuesto por SAVIGNY (vid., Sistema de Derecho Romano actual, Madrid, 1876, $2^{\mathrm{a}}$ ed. págs. 65 a 66) tal y como se estudia detenidamente en «Examen crítico de los fundamentos dogmáticos y jurisprudenciales de la expromisión y del artículo 1.205 del Código civil español (La vicenda modificativa, la sucesión singular de las deudas, el programa de la prestación y la aplicabilidad de ciertos principios contractuales» (vid., MORETón SANZ, ADC, cit.).

${ }^{75}$ Como es sabido, en el campo del derecho sucesorio no se produce la novación. En la transmisión mortis causa no se requiere la creación de un nuevo título; antes bien, el heredero ocupa el lugar del causante. Como recoge SALvador Coderch, WINDSCHEID resumía que «lo que caracteriza a la sucesión universal mortis causa, frente a otros títulos, es la no creación de un nuevo título adquisitivo autónomo (para los derechos) y la ausencia de novación (para las deudas)». El título de heredero tiene como efecto principal la asunción de deudas sin novación, toda vez que «tiene lugar el ingreso o la entrada del título en la relación jurídica y no sólo en la titularidad» [Pandekten (n. 8), I, parágrafo 64, apud. cit., «El título de heredero. Discurso de contestación al de investidura de Juan Berchmans VALLET DE GOYTISOLO como Doctor 


\section{RELEXIONES CONCLUSIVAS}

La delimitación de los presupuestos específicos de la expromisión se encuentra con el relativo obstáculo de su tradicional estudio en sede de requisitos generales aplicables a la novatio, presentados siempre sin las debidas singularidades que exige el análisis de la asunción espontánea de deuda.

En términos generales, los requisitos de la novatio se refieren a la existencia de una relación válida sobre la que se aplica el ánimo o intención novatoria de las partes para sustituir el objeto o el sujeto de dicho vínculo preliminar, con la pervivencia de algo idéntico de la relación precedente o idem debitum.

Elemento lógico para cualquier alteración o modificación de una relación resulta ser, precisamente, su preexistencia y validez. Sentado este presupuesto, y tras su examen correspondiente, cabe afirmar que cualquier relación, independientemente de la fuente de la que haya nacido, será apta para ser modificada, sin que su origen convencional o incluso legal sea un obstáculo jurídico eficaz. En este sentido, cabe destacar que, en su caso, tanto las partes como la norma de la que surja una obligación, pueden imponer la imposibilidad de cambios subjetivos sobrevenidos. Dicho esto, y teniendo en cuenta el origen legal de la responsabilidad extracontractual, ha de señalarse que nada impide la realización de cambios subjetivos pasivos en dichas relaciones y que, a mayor abundamiento, tampoco el acuerdo expromisorio habrá de presentar consecuencias extintivas en el vínculo modificado. De modo que no se comparten las tesis que, aún sin negar la hipótesis de la sustitución del deudor en las relaciones extracontractuales, defienden que ante un cambio tan sustancial como es el subjetivo pasivo se debe producir, necesariamente, la extinción de la relación previa y su transformación por una obligación contractual.

Por el contrario, y, a mi juicio, que el efecto participe del acuerdo que produce la modificación, no autoriza a que se sostenga que la naturaleza del acuerdo sea también la de la relación resultante. Resulta éste un argumento tautológico ya que, en suma, se parte de la extinción y no del acuerdo que la genera.

Honoris Causa por la Universidad Autónoma de Barcelona», RDN, XXXII, CXXVII, 1985, pág. 411]. Sobre el distinto tratamiento que recibe el legatario frente al heredero como sucesor de las relaciones pasivas de su causante, vid., CUADRADo IgLESIAS, «Responsabilidad por razón de legados», Estudios jurídicos en Homenaje al Prof. Díez PICazo, Cabanillas Sánchez (Coord.), 4, 2002, Madrid, págs. 345 y sigs. 
En síntesis, dada una relación nacida de las fuentes prevenidas en el Código civil, podrá operar sobre dicha obligación cualquier acuerdo válido, convenio cuyo efecto será el mantenimiento de las cualidades y propiedades del vínculo previo. Por tanto, la fuente modificativa no altera la naturaleza de la relación sobre la que opera sino que, al contrario, subsiste alterada en los términos que hayan acordado las partes. Defender lo contrario es sostener que cabe la novación de la causa y del sujeto simultáneamente, cuando sin duda, una alteración tan radical ha de producir la extinción sin subsiguiente reemplazo por otra.

Una cosa es que el acuerdo de asunción suscrito entre un tercero y el titular de dicho vínculo presente naturaleza contractual y otra distinta es que, mediante dicho convenio, se altere la naturaleza extracontractual precedente. Ha de tenerse en cuenta que la causa de esa asunción de deuda practicada, en nuestro caso recurriendo a un pacto expromisorio, será la que presente la relación extracontractual. Pero, diferente de la causa del acuerdo expromisorio - que es la asunción de la obligación precedente- es la naturaleza contractual del pacto de asunción; como diversa es la naturaleza del acuerdo asuntivo de los efectos que produce.

Con todo, igualmente se ha de advertir que la transmisibilidad pasiva es susceptible de negociación en la relación preliminar, de modo que serán válidos los acuerdos por los que las partes, en el ejercicio de la autonomía de la voluntad privada, se autoimpongan la intransmisibilidad de una o de todas las obligaciones integradas en un vínculo.

En cuanto a los límites a la transmisibilidad de la conducta comprometida, en el caso de las obligaciones de hacer, quedarán sometidas tanto al consentimiento del acreedor como a la propia disponibilidad que sobre la cosa tenga quien pretenda asumir el cumplimiento de su entrega. Por su parte, y en cuanto a la sucesión pasiva de las obligaciones negativas, y el problema de la transmisión de la prestación sin el interés, se trata de disquisiciones, a mi juicio, estériles ya que bastará con que el acreedor de dicha prestación negativa acepte el cambio de sujeto pasivo para que así sea exigible y observable por quien haya ocupado el lugar de otro. Y si habiéndose aceptado por el titular del derecho de crédito el cambio de sujeto pasivo, el antiguo incumpliese, es decir, incurriese en la obligación en cuestión, las consecuencias indemnizatorias del incumplimiento recaerán sobre quien asumió la de otro.

En las obligaciones de resultado y de medios, en las primeras se antoja sencilla su transmisibilidad; en las segundas, el concurso de la 
lex artis dificulta la libre cesión de las obligaciones. Con todo, nuevamente, se refleja el contenido del artículo del 1.205 del Código civil, por lo que si el acreedor consiente resultará posible incluso en éstas últimas, sustituir al sujeto comprometido.

Cabe también la sustitución de las obligaciones, que no de los derechos, en las relaciones bilaterales correspectivas; si en un contrato bilateral se cede la posición contractual íntegra estaremos ante una cesión de contrato, figura atípica en la que, de nuevo, se reproduce con fuerza la necesaria presencia del consentimiento de la totalidad de los componentes subjetivos implicados y con ello, el contenido del artículo 1.205 del Código civil español.

Profesora Contratada Doctora del Departamento de Derecho Civil de la UNED. Miembro del Grupo de Investigación Consolidado "Protección civil de la persona», (Investigador responsable Prof. Dr. D. Carlos Lasarte Álvarez, Catedrático de Derecho civil de la UNED) y del Grupo «Perspectivas de futuro de las políticas de familia», de la Universidad de Alcalá. 